\title{
Review
}

\section{Multilayer Reflective Coatings for BEUV Lithography: A Review}

\author{
Paul C. Uzoma ${ }^{1,2}$, Salman Shabir ${ }^{1}$, Huan $\mathrm{Hu}^{1}$, Paul C. Okonkwo ${ }^{3}$ and Oleksiy V. Penkov ${ }^{1,4 *}$
}

1 ZJU-UIUC Institute, International Campus, Zhejiang University, Haining, 31400 China.

2 Department of Polymer and Textile Engineering, Federal University of Technology, P.M.B. 1526, Owerri 460114, Nigeria.

3 Mechanical \& Mechatronics Engineering Department, College of Engineering, Dhofar University, Salalah, Oman

4 Department of Mechanical Science and Engineering, the University of Illinois at Urbana-Champaign, Urbana, Illinois 61801, USA.

* Correspondence: oleksiypenkov@intl.zju.edu.cn

\begin{abstract}
The development of microelectronics is always driven by reducing transistor size and increasing integration, from the initial micron-scale to the current few nanometers. The photolithography technique for manufacturing the transistor needs to reduce the wavelength of the optical wave, from ultraviolet, deep, to the existing extreme ultraviolet light. One approach toward decreasing the working wavelength is using lithography based on beyond extreme ultraviolet radiation (BEUV) with a wavelength around $7 \mathrm{~nm}$. The BEUV lithography relies on advanced reflective optics such as periodic multilayer film X-ray mirrors (PMMs). PMMs are artificial Bragg crystals having alternate layers of "light" and "heavy" materials. The periodicity of such a structure is relatively half of the working wavelength. Since a BEUV lithographical system contains at least 10 mirrors, optics' reflectivity becomes a crucial point. The increasing of a single mirror's reflectivity by $10 \%$ will increase the system's overall throughput by 6 times. In this work, the properties and development status of PMMs, particularly for BEUV lithography, were reviewed to gain a better understanding of their advantages and limitations. Emphasis was given to materials, design concepts, structure, deposition method, and optical characteristics of these coatings.
\end{abstract}

Keywords: BEUV lithography; Multilayer mirrors; X-ray optics; reflectivity

\section{Introduction}

X-Ray Optics is one of the key technologies in various scientific, engineering, and industrial applications. This technology has attracted intensive attention worldwide due to its importance [1-4]. Developing a local technological chain to design and manufacture high-reflective x-ray optical components is crucial for national economics and security. These components are vital for various scientific and technical fields such as lithography, high-resolution microscopy, X-ray fluorescence analysis, synchrotrons, free-electron lasers, space astronomy, etc.

Among these, one of the most critical applications is next-generation lithography. In the microelectronics industry, there is an unceasing global trend of scaling down the manufacturing procedures to increase the operating frequency and decrease the power consumption and enhancing the computational capacity of microprocessors (Figure 1) [5-7]. So, increasing the resolution of the lithography equipment employed in the industry and the associated decrease in the working wavelength of the required light beam is the main technical route agreed by industry and academia [8]. 


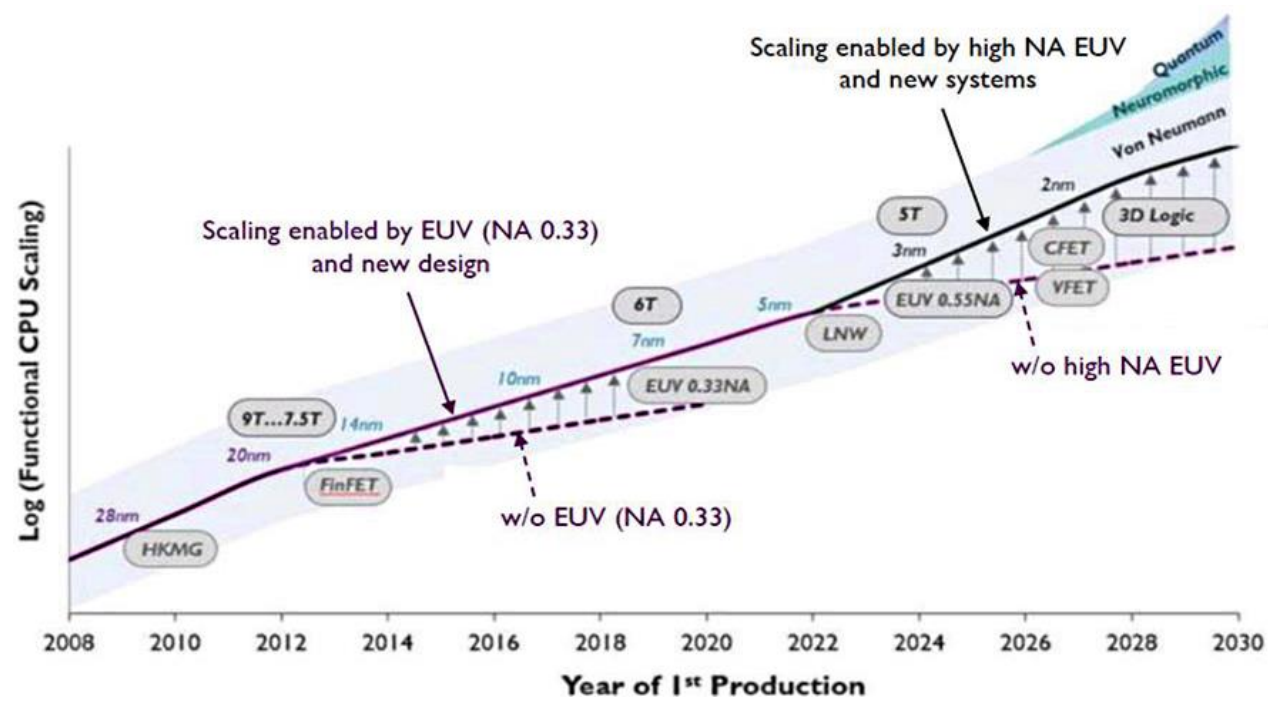

Figure 1. Technology node scaling is driven by the development of lithography. EUV will lead the industry in the next decade. Reprinted from [7] Courtesy of IMEC.

Lately, the resolution has been enhanced by substituting the deep ultraviolet (DUV) wafer scanners with novel devices that use soft x-ray radiation, also called extreme ultraviolet (EUV) radiation at $\lambda=13.5 \mathrm{~nm}$ [5]. A further reduction in the working wavelength to $6.7 \mathrm{~nm}$ and the use of beyond extreme ultraviolet (BEUV) radiation will boost the performance of microprocessors even more [5, 9]. Significant efforts were directed into this direction by ASML, which is the world's largest manufacturer of DUV and EUV lithographical equipment [10-14].

Soft X-rays exhibit a higher degree of absorption in all materials which has necessitated the use of reflective optics. Thus, the reflectivity of X-Ray optics is crucial for the efficiency of lithographical stepper machines. Figure 2 illustrates the optical system of the typical stepper machine used in lithography [15]. As can be seen, it contains at least 3 mirrors in the illuminator optics and 6 mirrors in the projection optics sections. The overall reflectivity of such an optical system is approximately one hundred times lower than the reflectivity of a single mirror due to the multiple reflections [16, 17]. Increasing each mirror's reflectivity from 53 to $65 \%$ will increase the integral throughput of the system by $\sim 7$ times. Thus, even a minimal improvement in reflectivity gives an immediate boost to the performance of lithographical systems which includes the spatial resolution, EUV light intensity, and speed. Also, it reduces the overall production cost by decreasing the exposition time

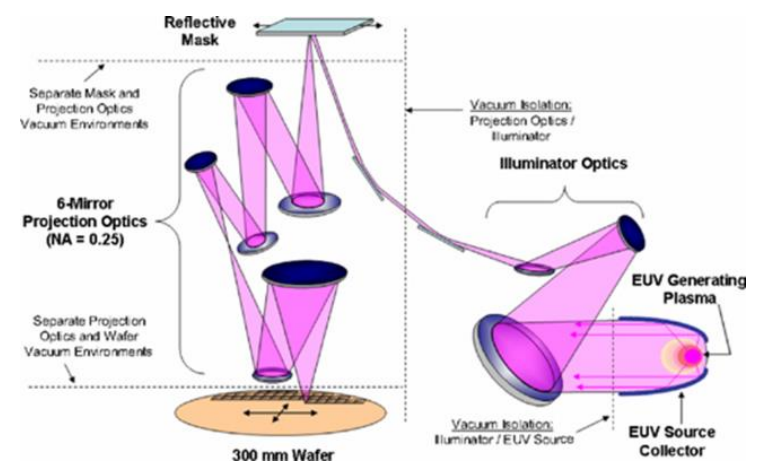

Figure 2. Schematics of the optical system of a lithographical stepper machine. Reprinted from [15].

The weak reflection of soft X-ray radiation by solids demands advanced reflective optical equipment. Immediately after the discovery of X-rays, it was stated that the refractive index of all materials is very small $\left(\sim 10^{-5}\right)$ [18]. Later, by discovering X-ray diffraction 
from crystals, the method of deflecting $X$-rays was provided for the first time [18]. A new version of X-ray diffraction has evolved over the last 25 years by building well-defined artificial diffracting structures instead of natural crystals to manipulate X-rays. Usually, such artificial structures consist of periodically alternated nanolayers of two materials, as shown in Figure 3. Thus, the reflectivity of X-rays is amplified due to the multiplication of interfaces. Such structures are called periodical multilayer X-ray mirrors (PMMs).

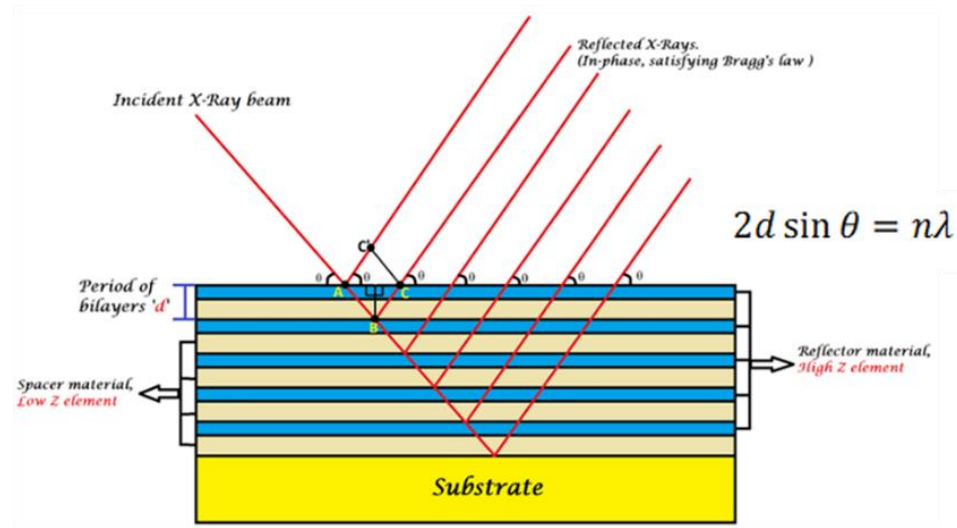

Figure 3. Schematic view of constructive interference from interfaces of a multilayer.

PMMs are known as artificial Bragg crystals having alternate layers of "light" and "heavy" materials (Figure 2); they are also called "spacer" and "absorber." The periodicity of such a structure is almost half of the working wavelength when the angle of incidence (AOI) is near $90^{\circ}[17,19]$. PMMs realize high reflectivity by the constructive interference of light reflected from the interfaces of assembled layers of different optical contrasts. It is important to note that the refractive index in the $\mathrm{X}$-ray range is complex and equals to 1 $\delta+\mathrm{i} \beta$, where $\delta$ is the refractive index decrement and $\beta$ represents the absorption index. Therefore, at any given wavelength, materials with a high $\delta$ and a low $\beta$ act as a reflective layer, while those with a low $\delta$ and a low $\beta$ serve as spacer layers. An array of layers with high and low $\delta$ (alternated reflectors and spacers in a stack) provides optical contrast as shown in Figure 3. Both the reflector and spacer layers need a low $\beta$ to minimize any loss of light by absorption. For instance, at a wavelength of above $12.8 \mathrm{~nm}$, molybdenum and silicon can serve as a pair of reflector/spacer materials and work together to serve as PMMs.

\section{Materials and Design}

The design of high-reflective PMMs for the specific wavelength includes two essential steps. The first step is the choice of a material pair. The selection is based on the optical properties of materials in the given wavelengths range. For example, $\mathrm{Mo} / \mathrm{Si} \mathrm{PMMs}$ are primarily used for the wavelength of $13.5 \mathrm{~nm}$ (EUV), Mo/B and La/B PMMs are excellent for $6.7 \mathrm{~nm}$ (BEUV) since Boron has lower absorption in this range compared to silicon [2024]. Co/C PMMs are the most effective for the shorter wavelength range of $4.4-4.5 \mathrm{~nm}$ [25].

The second step is selecting the thickness of the individual layers and the number of layers. This step is generally based on computer simulations [18]. For instance, for BEUV radiation and $5^{\circ}$ angle of incidence off normal, the thicknesses of B (light) and Mo (heavy) layers should be around 2.25 and $1.12 \mathrm{~nm}$, respectively. Also, for reflectivity at a nearnormal angle of incidence (AOI), La/B4C PMMs taken as very high reflective coatings operating at $\lambda=6.65 \mathrm{~nm}$ mostly require 200 periods of $B_{4} C$ layers with $2.0 \mathrm{~nm}$ thickness $B_{4} C$ and La layers with $1.6 \mathrm{~nm}$ thickness.

For the first time, the material-based design of PMMs for 2-12 nm wavelength range was done by Claude et al. [22]. It was revealed that Mo/Si PMMs are not fitting for the 
BEUV range due to the high absorption of Si mentioned above. Instead, following their calculations, Mo/B PMMs should show high reflectance at $6.6-11.5 \mathrm{~nm}$ wavelengths. A plethora of studies has been carried out on $\mathrm{Mo} / \mathrm{B}_{4} \mathrm{C}, \mathrm{Pd} / \mathrm{B} 4 \mathrm{C}$, and $\mathrm{La} / \mathrm{B}_{4} \mathrm{C}$ PMMs that use boron carbide $\left(\mathrm{B}_{4} \mathrm{C}\right)$ as a replacement for $\mathrm{B}$ [26-30].

From various literature, Boron has been identified as the best material for the spacer layer for the BEUV range. But B-based PMMs have been seldomly investigated notwithstanding their superior theoretical performance compared to other materials. The discrepancy in the volume of study is ascribed to the complexity of the deposition of the highquality B-based PMMs. Much as boron carbide films are nicely produced by magnetron sputtering, pure Boron is challenging to sputter due to its low atomic number [31]. The complication in the production of B-based PMMs is also caused by the dielectric nature of Boron. An extended-time magnetron sputtering of the dielectric target can cause instability of the deposition process because of the electrical charging of surfaces. In the case of $\mathrm{B}_{4} \mathrm{C}$, the behavior of the deposition procedure was more certain because it is easier to deposit.

As a result, for Mo/B PMMs produced by e-beam evaporation, the experimentally determined reflectivity was less than $10 \%$ [22]. Thus, Boron in the PMMs was replaced mainly by the less efficient $\mathrm{B}_{4} \mathrm{C}$. For comparison, the best $\mathrm{B}_{4} \mathrm{C}$-based $\mathrm{PMMs}$ such as $\mathrm{La} / \mathrm{B}_{4} \mathrm{C}$, $\mathrm{Mo} / \mathrm{B}{ }_{4} \mathrm{C}, \mathrm{Sb} / \mathrm{B}_{4} \mathrm{C}$, etc., demonstrated the reflectivity of around $20-40 \%$ at the wavelength of $6.6 \mathrm{~nm}[32][26,33]$. In the recent study published by Zhu et al. in 2020, the peak reflectivity of $10 \%$ was recorded for $\mathrm{Mo} / \mathrm{B}_{4} \mathrm{C}$ PMMs [34]. In general, the low reflectivity of $\mathrm{B}_{4} \mathrm{C}$-based PMMs should be attributed to the relatively high absorption of Carbon at the $6.6 \mathrm{~nm}$ wavelength and various structural imperfections.

\section{Structural and optical properties}

The nanostructure of the PMMs has a pivotal impact on optical behavior. The nanostructure can be controlled by a comprehensive understanding of the relationship between the structure and deposition conditions. The structural defects, like interface roughness and intermixing between layers, will decrease the interfaces' sharpness and reduce the overall reflectivity $[35,36]$. Thus, without the knowledge of the real structure, it is impossible to correctly predict the reflectivity of PMMs. That is why multiple studies in this field have been performed especially the structure of PMMs such as Sc/Si [37, 38], and $\mathrm{Co} / \mathrm{C}[39]$.

The intermixing occurs in many nanolayered systems because of solid-state chemical reactions. For example, the deposition of Mo on the top of Si led to the formation of a thin layer of molybdenum disilicide $\left(\mathrm{MoSi}_{2}\right)$. In the case of $\mathrm{Mo}$ and $\mathrm{B}$, the appearance of molybdenum diboride $\mathrm{MoB}_{2}$ occurred (Figure 4). Intermixing in PMMs is considered a structural imperfection because intermixed layers reduced the sharpness of the interface and deteriorated the reflectivity despite their low thickness (around $1 \mathrm{~nm}$ ) [37]. For instance, Sertsu et al. [40] observed a peak reflectivity value of $6.65 \%$ at $\lambda=6.9 \mathrm{~nm}$ and $10^{\circ} \mathrm{AOI}$ for $\mathrm{B}_{4} \mathrm{C} / \mathrm{CeO}_{2}$ multilayer. But the value is 4.4 times lower than the calculated value due to significant interface diffusion. Therefore, suppression or even full illumination of the intermixing is crucial for the improvement of the reflectivity of PMMs. Besides, the knowledge about intermixing mechanisms in $\mathrm{Sc} / \mathrm{Si}$ and $\mathrm{Co} / \mathrm{C}$ PMMs developed in early studies [37] [38] [39] allowed suppression of the intermixing by introducing diffusion barriers and improve the temperature stability of PMMs [41] [42, 43]. 

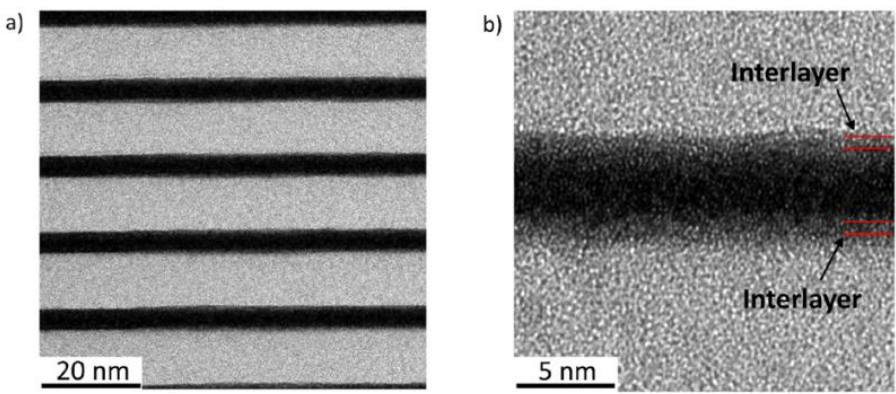

Figure 4. Illustration of intermixing in PMMs. a) Cross-sectional High-Resolution TEM image of Mo/B PMMs; b) Magnification of the central area. Reprinted from [44] with permission from Elsevier.

In addition to the intermixing, the interface roughness is another factor crucial for reflectivity. It was shown that adjusting the pressure in the deposition step can significantly reduce the interface roughness in Mo/Si PMMs [45]. On the other hand, the roughness is also affected by the thickness of individual layers [46]. Thus, these factors should be considered simultaneously. It was demonstrated for EUV PMMs such as Mo/Si and $\mathrm{Cr} / \mathrm{Sc}$ that ion polishing reduced the roughness $[47,48]$. Most recently, ion polishing was used for W/Si PMMs [49]. In the last case, 0.1 to $0.5 \mathrm{~nm}$ of each Si layer were etched with $100 \mathrm{eV}$ Ar ions. The analysis revealed that ion polishing reduces the vertical propagation of roughness from layer to layer by a factor of two and favorably affecting the lateral correlation length.

While significant efforts were directed to the investigation and improvement of $\mathrm{B}_{4} \mathrm{C}$ based PMMs, the structure of the Mo/B PMMs remains virtually unknown due to the complications in the synthesis earlier mentioned. The initial study on the optical properties of Mo/B PMMs was done in 1996, and it did not include a comprehensive structural analysis [22]. Due to the difficulties of Boron sputtering mentioned above, other research in this field were not performed for several decades. But recently, several groups reported the successful synthesis of B-based PMMs.

The manufacturing of La/B PMMs was reported by Makhotkin and co-workers [28]. Despite high expectations, these PMMs showed a low reflectivity because of the intermixing of the layers and the high interface roughness. Besides, the active chemical properties of La make it challenging to preserve the reflectivity of La-based PMMs [34]. To improve the reflectivity of $\mathrm{La} / \mathrm{B}$ PMMs, the nitridation of the interfaces between $\mathrm{La}$ and $\mathrm{B}$ was recommended [10]. The nitridation of La represses the intermixing of La and B, thereby enhancing the optical contrast between $\mathrm{La}$ and $\mathrm{B}$. $\mathrm{Xu}$ et al. used the nitridation process to improve Pd/Y PMMs at a wavelength of 9.2-9.3 nm [50]. In both cases, the reflectivity of the PMMs was significantly improved by nitridation. Nonetheless, periodicity errors developed because of the technical complexity of selective nitridation. These errors prevent reaching theoretical reflectivity. Thus, the deposition technique should be improved to avoid the adverse effects associated with nitridation.

\subsection{Structure and optical characteristics of Molybdenum-based BEUV PMMs}

In 1996, Claude and co-workers synthesized 100-period Mo/B multilayers using a deposition system that contained a cryopump vacuum chamber with two magnetron sputtering guns of $1.5 \mathrm{~cm}$ diameter [22]. This mirror exhibited a peak reflectance of $\sim 9.4 \%$ at $\lambda=6.67 \mathrm{~nm}$ and $5^{\circ}$ angle of incidence. According to the low-angle X-ray diffraction (LAXD) spectra, they assumed that the general structure of the $\mathrm{Mo} / \mathrm{B}$ multilayer was satisfactory with $\sim 0.35 / 0.65$ interface width.

Recently, Penkov et al. successfully synthesized Mo/B PMMs with the estimated reflectivity value of $53 \%$ [44]. It was shown that $\mathrm{Mo} / \mathrm{B}$ PMMs deposited by magnetron sputtering are comprised of smooth, amorphous Mo and B layers divided by $\sim 0.4 \mathrm{~nm}$ thick interlayers, which are a mixture of $\mathrm{MoB}$ and $\mathrm{MoB}_{2}$. The average density of the interlayers is close to that of $\mathrm{MoB}_{2}$. From these experimental observations, the optical performance in 
the BEUV range was calculated considering the real nanostructure of Mo-B interfaces. The computer modeling signified that the Mo/B PMMs should display a reflectivity of $\sim 53 \%$ at a working $\lambda=6.7 \mathrm{~nm}$ (Figure 5) [44]. Such reflectivity is many times higher than one of the $\mathrm{B}_{4} \mathrm{C}$ structures reported by other researchers $[34,40,51]$. Table 1 gives the summary of the recent achievements of PMMs reflectivity in the BEUV range.

Table 1. Reported reflectivity of various PMMs for BEUV range

\begin{tabular}{ccccc}
\hline PMMs & $\begin{array}{c}\text { Theoretical } \\
\text { Reflectivity }\end{array}$ & Real Reflectivity & Drawbacks & Reference \\
\hline LaN/B & $75 \%$ & $64 \%$ & $\begin{array}{c}\text { Low time stability, } \\
\text { manufacturing com- }\end{array}$ & Kuznetsov,2015 [10] \\
& & & $\begin{array}{c}\text { plexity } \\
\text { Low reflectivity }\end{array}$ & Zhu, 2020 [34] \\
Mo/B4C & $48 \%$ & $10 \%$ & $\begin{array}{c}\text { No experimental con- } \\
\text { firmation }\end{array}$ & Penkov, 2021[44] \\
Mo/B & $65 \%$ & $53 \%$ & Low time stability & Naujok, 2015 [27] \\
\hline La/B4C & $69.7 \%$ & $54.4 \%$ & &
\end{tabular}

As for the Mo/B PMMs, even the expected reflectivity of 50-53\% was still smaller than the theoretical maximum, which was around $70 \%$. This difference in reflectivity was attributed to the formation of interlayers, high interface roughness, and bad structural uniformity. The first two factors reduced the sharpness of interfaces between Mo and B within the periodical stack. These factors led to the reduction of reflectivity.

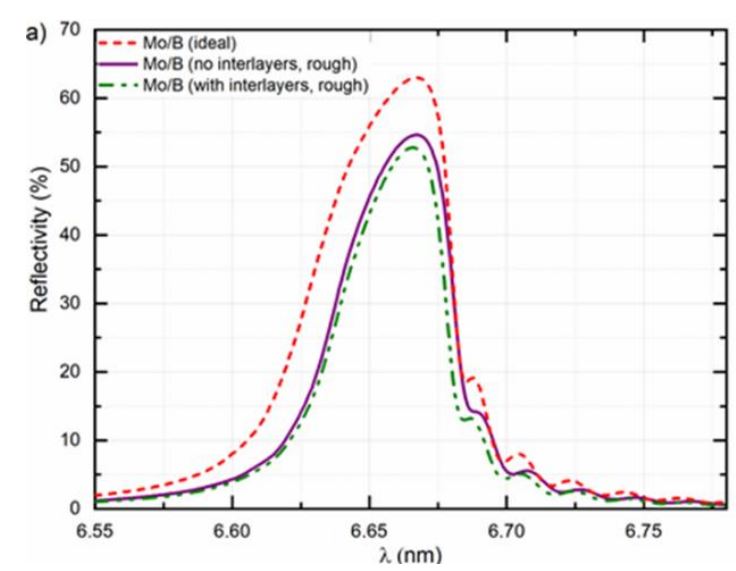

Figure 5. An analogy of the simulated peak reflectivity of varying PMM models at $\lambda=6.7 \mathrm{~nm}$ and $5^{\circ}$ off normal angle of incidence: ideal Mo/B multilayer; $\mathrm{Mo} / \mathrm{B}$ multilayer with interface roughness; real Mo/B multilayer with interlayers. Reprinted from [44] with permission from Elsevier.

The structural uniformity implies the regularity of the thickness of the layers and interface structure across the whole multilayer stack. Apparent errors in the thickness of individual layers or their continuous variation (drifting) caused by various factors deteriorate the uniformity. Preserving structural uniformity is essential for maintaining Bragg's diffraction condition. The nature of the periodicity is defined mainly by the deposition rate's time stability and maintenance of the substrate temperature [24]. The degree of the uniformity could be quickly evaluated by Low-angle X-ray reflectometry [44]; it manifests itself in the form of broadening of diffraction peaks, as shown in Figure 6. The real structure suffers from the gradual increase of the interlayers due to the rising of the substrate temperature during the deposition. The theoretical model implies the ideally periodical structure. The inset shows the broadening of the diffraction peak due to low structural uniformity. 


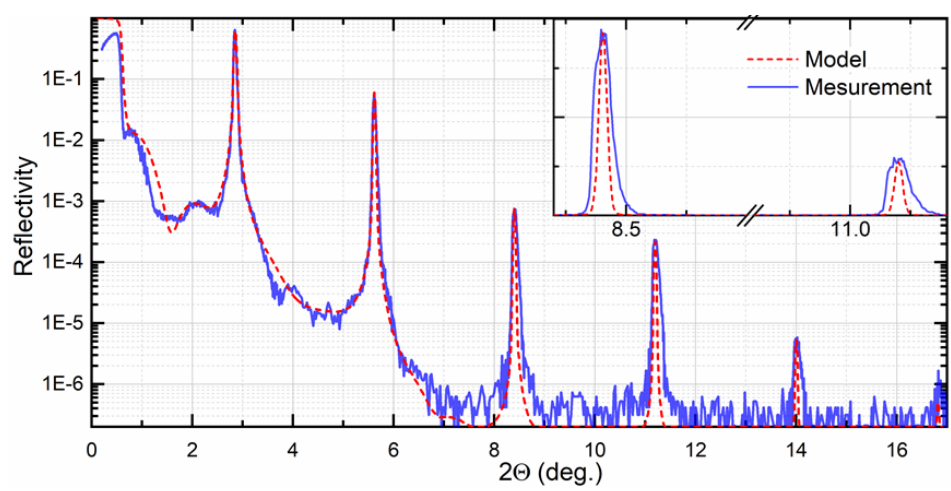

Figure 6. Comparison of measured and calculated low-angle reflectivity curves for Mo/B PMMs having 250 pairs. The inset shows the broadening of the diffraction peak. Adapted from [44] with permission from Elsevier.

It was reported that the structure and reflectivity of the Mo/B PMMs were susceptible to deposition temperature. Increasing the temperature led to the larger thickness of interlayers [44]. In the initial study, the temperature was not controlled; it was just recorded as the magnetron power function. Since the deposition temperature was varied during the deposition, a corresponding increase in the roughness and thickness of interlayers along the multilayer stack was expected, leading to a deterioration of the structural uniformity. Since it was considered, the total reflectivity of Mo/B PMMs can be lower than the theoretical estimation. Besides, it should be noted that high structural uniformity allows effective use of computer simulation of Low-angle XRD for studying interfaces with sub-nanometer resolution [18]. Applying this method gives new insight into the fundamental mechanism of low-scale interlayer mixing during the manufacturing of PMMs.

\subsection{Structure and optical characteristics of Lanthanum-based BEUV PMMs}

La-based PMMs have been shown to possess a greater reflectance than Mo-based PMMs due to their bulk optical properties and are therefore preferred candidates for applications like EUV lithography which requires high photon transmission. $\mathrm{La} / \mathrm{B}_{4} \mathrm{C} \mathrm{PMMs}$ have also been considered for use in X-ray fluorescence spectroscopy [7], particularly for boron detection [8]. The theoretical reflectivity of La/B-based PMMS is $>80 \%$ at $6.6 \mathrm{~nm}$ but the highest experimentally obtained reflectivity is still significantly lower. Makhotkin et al. prepared La/B PMMs with different periods (7.8 - $3.2 \mathrm{~nm}$ wavelength range) [28]. In the La/B PMMs optical characterization, their choice of angle of incidence in respect to the surface normal was made to exhibit the maximum reflectance at $6.8 \mathrm{~nm}$. The measured reflectivity was compared to the calculated maximum reflectivity that is computed for a standard 40 periods La/B multilayer without interface roughness, employing the bulk values for La and B densities and the ratio of as-deposited La and B layer thickness. Their results proved that increasing the thickness of the multilayer periods can decrease the difference between the calculated and measured reflectivity as shown in Figure 7. Besides, they showed that the calculated reflectance values can be achieved experimentally by improving the multilayer interface quality. 

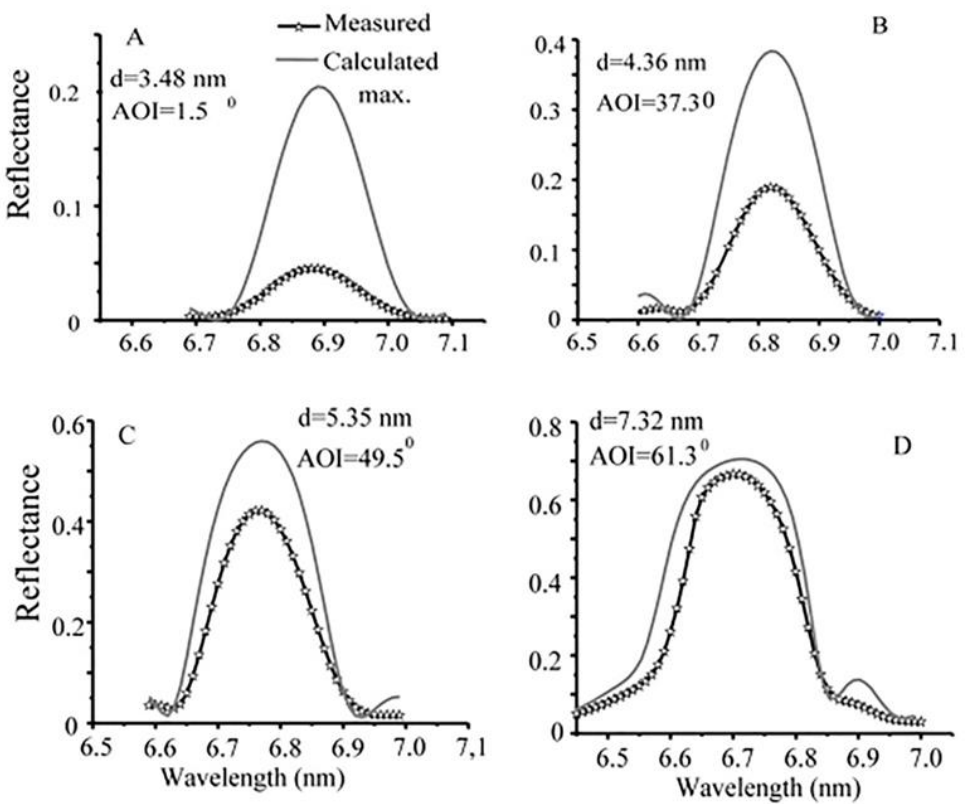

Figure 7. Calculated and Measured BEUV reflectivity for e-beam deposited 40-period La/B PMMs with different periods. Reprinted with permission from [28] ( T) The Optical Society.

Platonov and co-workers compared the structural and optical performance of $\mathrm{La} / \mathrm{B}_{4} \mathrm{C}$ and $\mathrm{La}_{2} \mathrm{O}_{3} / \mathrm{B}_{4} \mathrm{C}$ multilayers [52]. The measured maximum peak reflectivity of $\mathrm{La} / \mathrm{B}_{4} \mathrm{C}$ is $48.9 \%$ at $\lambda=6.68 \mathrm{~nm}$, while $\mathrm{La}_{2} \mathrm{O}_{3} / \mathrm{B}_{4} \mathrm{C}$ showed $39.2 \%$ maximum reflectivity at the same wavelength. But, at $\lambda=6.63 \mathrm{~nm}$ the reflectivity of $\mathrm{La}_{2} \mathrm{O}_{3} / \mathrm{B}_{4} \mathrm{C}$ is $39.2 \%$. Such strong reflectivity reliance on the wavelength is ascribed to the fast-changing of boron optical behavior in the neighborhood of $\mathrm{K}_{\alpha}$ absorption edge at $6.57 \mathrm{~nm}$. They observed that the bandwidth of the reflectivity curves was $\sim 20 \%$ lower than that obtained in the ideal structures. It demonstrates an active commingling of the layer materials and a broad thickness of the transition layer between Lanthanum and Boron carbide-based layers. Moreover, $\mathrm{La}_{2} \mathrm{O}_{3} / \mathrm{B}_{4} \mathrm{C}$ multilayer showed a greater level of imperfections leading to much-reduced performance.

In an attempt to replace $\mathrm{B}_{4} \mathrm{C}$ with a more boron-rich $\mathrm{B} 9 \mathrm{C}$, Andreev et al. obtained $38 \%$ reflectivity for $\mathrm{La} / \mathrm{B} 9 \mathrm{C}$ PMMs, which is lower compared to the reported $44 \%$ reflectivity of $\mathrm{La} / \mathrm{B}_{4} \mathrm{C}$ multilayer implying that more boron-rich carbide does not translate to higher reflectivity [53]. It also suggests that variations in the growth behavior of the different materials can have a significant impact on optical performance and may reverse any theoretically predicted enhancements [28]. The major reason for the variation between the experimental and the theoretical reflectance of PMMs has been identified as the expansion of the boundaries in the multilayer structures because of the mixing of the materials.

Lanthanum was shown to form compounds with Boron and Carbon $\left(\mathrm{LaB}_{6}\right.$ and $\left.\mathrm{LaC}_{2}\right)$ in $\mathrm{La} / \mathrm{B}_{4} \mathrm{C}$ PMMs [54]. Besides, materials like $\mathrm{Mo}, \mathrm{Cr}, \mathrm{Sn}$, and $\mathrm{C}$ have been experimented with as an anti-diffusion barrier between $\mathrm{La}$ and $\mathrm{B}_{4} \mathrm{C}[53,55]$. To confirm the barrier properties of the mentioned materials, Andreev and co-workers analyzed the interaction between $\mathrm{La} / \mathrm{Cr} / \mathrm{B} 4 \mathrm{C}, \mathrm{La} / \mathrm{Mo} / \mathrm{B}_{4} \mathrm{C}$, and $\mathrm{La} / \mathrm{Sn} / \mathrm{B}_{4} \mathrm{C}$ with periods $7-8 \mathrm{~nm}(\mathrm{~N}=60)$ and approximately the same layer width ratio $(b \approx 0.5)$. Their results showed that $\mathrm{La} / \mathrm{Sn}$ failed because $\mathrm{Sn}$ is prone to gathering into drops during the production process. Besides, the reflection coefficient at $6.69 \mathrm{~nm}$ wavelength using $\mathrm{Mo}$ and $\mathrm{Cr}$ as anti-diffusion barriers are $9 \%$ and $4.2 \%$, respectively. These results are significantly lower than using $\mathrm{La} / \mathrm{B}_{4} \mathrm{C}$ without the barriers. They explained that the dielectric constants of $\mathrm{Cr} / \mathrm{La}$ and Mo/La layers are different from the tabulated values of the bulk materials, which might be due to the high chemical activity of La.

Chkhalo et al. compared the effect of Carbon as an anti-diffusion barrier [55]. They deposited carbon layers (0.25-0.3 nm thickness) on top of the $\mathrm{B}_{4} \mathrm{C}$ films to prevent direct contact between $\mathrm{La}$ and $\mathrm{B}{ }_{4} \mathrm{C}$. The results of $\mathrm{La} / \mathrm{B}_{4} \mathrm{C}$ and $\mathrm{La} / \mathrm{B}_{4} \mathrm{C} / \mathrm{C}$ PMMs Bragg-reflectivity 
measurements near $6.7 \mathrm{~nm}$ wavelength are given in Figure 8. The $\mathrm{La} / \mathrm{B} 4 \mathrm{C} / \mathrm{C}$ with Carbon acting as anti-diffusion layers gave the highest reflection coefficient of $58.6 \%$ at $6.661 \mathrm{~nm}$ wavelength. While the reflection coefficient of normal $\mathrm{La} / \mathrm{B} 4 \mathrm{C}$ is $40 \%$ at the same wavelength. Based on the small-angle X-ray diffraction $((\mathrm{Cu} \mathrm{k}-\alpha)$ measurements of the $\mathrm{La} / \mathrm{B} 4 \mathrm{C}$ sample (without carbon anti-diffusion barrier), the obtained interface parameters are as follows; thickness period $\mathrm{d}=3.35 \mathrm{~nm}$, and the portion of $\mathrm{La}$ in the period $\gamma_{\mathrm{La}}$ is $\mathrm{dLa} / \mathrm{d}=0.5$. The width of the La-on- $\mathrm{B}_{4} \mathrm{C}$ transitional region is $\sim 0.75 \mathrm{~nm}$, while the $\mathrm{B}_{4} \mathrm{C}$-on-La region is $\sim 0.35 \mathrm{~nm}$. The densities of the materials are QLa $=5.40 \mathrm{~g} \mathrm{~cm}^{-3}$ and QB4C $=1.8 \mathrm{~g} \mathrm{~cm}^{-3}$ (for the tabulated values QLa $=6.17 \mathrm{~g} \mathrm{~cm}^{-3}$ and $\mathrm{QB} 4 \mathrm{C}=2.0 \mathrm{~g} \mathrm{~cm}^{-3}$ ). The theoretical calculation also proved that the peak reflectivity of a mirror with the same parameters at $6.661 \mathrm{~nm}$ wavelength should be $40 \%$.
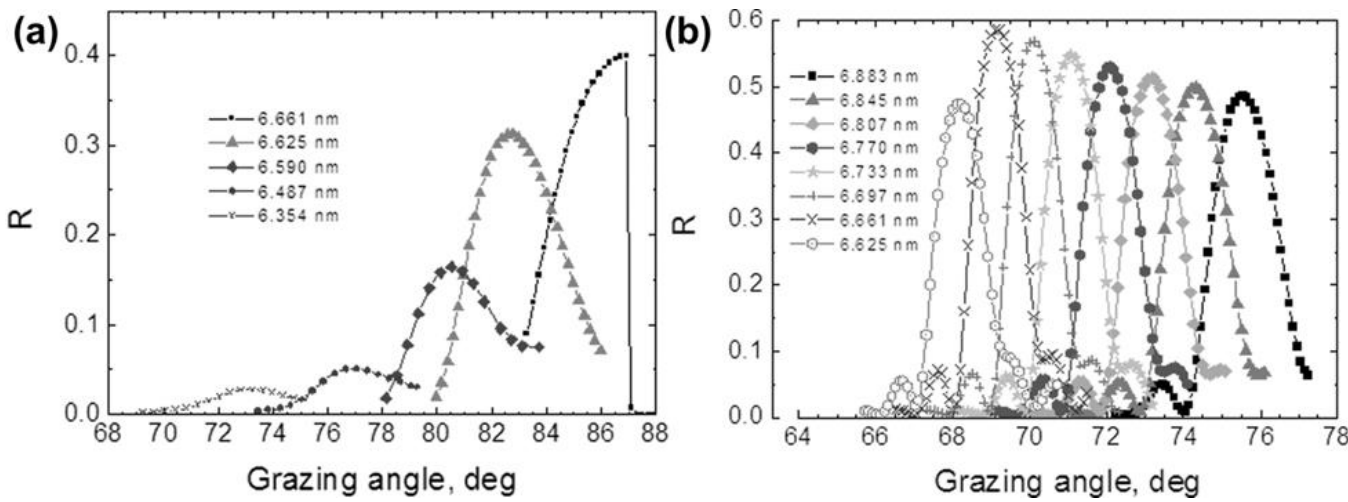

Figure 8. Angular dependence of reflectivity of (a) the $\mathrm{La} / \mathrm{B}_{4} \mathrm{C},(\mathrm{b}) \mathrm{La} / \mathrm{B}_{4} \mathrm{C} / \mathrm{C}$ PMMs taken in the spectral range of 6.6-6.9 nm wavelength. Reprinted from [55] with the permission of AIP Publishing.

\subsubsection{Nitridation of Lanthanum based PMMs}

Interfaces in PMMs for instance $\mathrm{B}_{4} \mathrm{C} / \mathrm{La}$ optics for B-K $\alpha$ reflectivity $(\lambda=6.65 \mathrm{~nm})$ have been shown to go through surface isolation and exothermic interlayer formation through $7 \mathrm{La}+6 \mathrm{~B}_{4} \mathrm{C} \rightarrow 4 \mathrm{LaB}_{6}+3 \mathrm{LaC}_{2}$ [54]. Also, vapor/sputter deposition of $\mathrm{B}_{4} \mathrm{C}$ happens in separate $\mathrm{B}$ and $\mathrm{C}$ atoms $[54,56]$, enhancing the $\mathrm{B} 4 \mathrm{C}$-on-La interface reactivity. Therefore, nitridation is employed to achieve chemically inactive, and high contrast interfaces which are essential in PMMs structures.

Looking at the formation enthalpy $\left(\Delta \mathrm{H}^{\text {for }}\right)$, absorption constant $(\beta)$, and refractive in$\operatorname{dex}(\mathrm{n})$ at $\lambda=6.65 \mathrm{~nm}$ of the compounds described in Table 2[57], it is shown that the passivation of the $\mathrm{B} 4 \mathrm{C} / \mathrm{La}$ interface can be achieved by nitridation which will lead to enhanced reflectivity. Besides, nitridation can repress roughening via grain formation [58] and diffusion at high temperatures. The values of $\Delta \mathrm{H}^{\text {for }}$ suggest that the $\mathrm{B}_{4} \mathrm{C} / \mathrm{LaN}$ and $\mathrm{BN} / \mathrm{LaN}$ interfaces are chemically dormant and are not affected by $\mathrm{LaB}_{6}$ and $\mathrm{LaC}_{2}$ interlayer formation. IMD-modelling $[57,59]$ shows that a $20 \%$ increase in peak reflectivity and bandwidth can be obtained in comparison to a 200 period $\mathrm{B}_{4} \mathrm{C} / \mathrm{La}$ PMMs when $0.3 \mathrm{~nm}$ of both the top and lower side of the La layer is replaced by $\mathrm{LaN}$ in a $\mathrm{B}_{4} \mathrm{C} / \mathrm{LaN} / \mathrm{La} / \mathrm{LaN}$ PMMs.

Table 2. The values of $\Delta \mathrm{H}^{\text {for }}$, $\mathrm{n}$, and $\beta$ (at $\lambda=6.65 \mathrm{~nm}$ ) for $\mathrm{LaN}, \mathrm{BN}, \mathrm{LaB}_{6}, \mathrm{LaC}_{2}, \mathrm{~B}_{4} \mathrm{C}$, and $\mathrm{La}$. Reprinted from [57] with permission from Elsevier.

\begin{tabular}{ccccccc}
\hline Compound & LaN & $\mathbf{B N}$ & $\mathbf{L a B}_{6}$ & $\mathbf{L a C}_{2}$ & $\mathbf{B}_{4} \mathbf{C}$ & $\mathbf{L a}$ \\
\hline$\Delta \mathrm{H}^{\mathrm{for}}(\mathrm{KJ} / \mathrm{mol})$ & -303 & -255 & -130 & -89 & -71 & 0 \\
$\mathrm{n}$ & 0.981 & 0.995 & 0.992 & 0.986 & 0.999 & 0.984 \\
$\beta\left(\times 10^{3}\right)$ & 1.420 & 0.894 & 0.853 & 0.996 & 0.528 & 1.075 \\
\hline
\end{tabular}

Tsarfati et al. [57] verified the IMD calculations on the optical and kinetics properties by studying nitridation and chemical reactivity in $\mathrm{La}$ and $\mathrm{B}_{4} \mathrm{C}$ layers. Their analysis on $\mathrm{B}_{4} \mathrm{C}$ and La layer nitridation by $\mathrm{N}^{2+}$ remedy proved that the $\mathrm{B} 4 \mathrm{C} /$ La interface gradient can 
be largely decreased by nitridation of the interface. From their bilayer observations, they concluded that nitridation can boost layer-by-layer growth both through chemical passivation and surfactant-mediated growth of diffusing $\mathrm{N}_{2}$ that is weakly bonded in dinitrogen complexes. In their explanation, the loosely bonded $\mathrm{N}$ or $\mathrm{N}_{2}$ in the $\mathrm{B}_{4} \mathrm{C}$ or La substrate layers partly diffuses into the adlayer causing surfactant mediated adlayer growth. Successive nitridation of the adlayer was seen to yield nitridated interfaces that are chemically inactive to $\mathrm{LaB}_{6}$ and $\mathrm{LaC}_{2}$ interlayer formation. $\mathrm{B}_{4} \mathrm{C}$ was observed to swell remarkably upon nitridation, whereas the $B$ content is lowered significantly. The optimum performance was obtained when the $\mathrm{La}$ and $\mathrm{B}_{4} \mathrm{C}$, or only the La layers are post-N-treated. Their experimental results were extrapolated using IMD modeling, which suggests $\sim 51 \%$ peak reflectivities at $\lambda=6.72 \mathrm{~nm}$ for a 200-period multilayer.

Makhotkin et al. [28] investigated the influence of two modes of nitridation on the optical performance. Herein, they employed magnetron sputtering since it is the frequently used technique for the deposition of multilayers consisting of a large number of periods. Two approaches; reactive magnetron sputtering of Lanthanum in a blend of $\mathrm{Ar}-$ gon and Nitrogen (represented as $\mathrm{La}(\mathrm{N}) / \mathrm{B}$ ) and post-treatment of the La layers by $\mathrm{N}_{2}$-ions (defined as La/N/B) were used to nitridate Lanthanum layers. $\mathrm{La}(\mathrm{N}) / \mathrm{B}$ and $\mathrm{La} / \mathrm{N} / \mathrm{B}$ PMMS having 175 periods were deposited to examine the obtainable normal incidence reflectance at $\sim 6.7 \mathrm{~nm}$ wavelength. In both cases, they observed that the nitridation of La significantly increased the optical contrast between La and B, and in turn increased the EUV reflectivity. However, the nitridation did not alter the total width of the interfaces, leaving enough room for further enhancement. Besides, the optical contrast of LaN/B multilayer stacks was limited by the presence of $\mathrm{N}$ atoms in the $\mathrm{B}$ layers. The normal incidence reflectivity of $\mathrm{La}(\mathrm{N}) / \mathrm{B}$ and $\mathrm{La} / \mathrm{N} / \mathrm{B}$ PMMs are $53 \%$ and $57.3 \%$, respectively. In both cases, the measured reflectivity is less than the $60 \%$ value shown by their simulations.

Also, they observed that the reflectance plot of the La/N/B PMMs revealed a significantly bigger width than the simulated plot as well as the measured $\mathrm{La}(\mathrm{N}) / \mathrm{B}$ multilayer. Furthermore, $\mathrm{La}(\mathrm{N}) / \mathrm{B}$ PMMs with $57.3 \%$ reflectivity is closer to the predicted value (60\%), implying that the $\mathrm{La}(\mathrm{N}) / \mathrm{B}$ multilayer deposition possess lower aperiodicity and no severe growth of the interface roughness. The higher aperiodicity of La/N/B PMMs can be interpreted by the disparity in the deposition process. The post-N-ion treatment is an extra step in the deposition operation. It may result in additional instability of the growth process that is best visible for a multilayer coating with a high number of periods.

Generally, complete passivation of LaN is preferred so to maximally prevent admixing between layers. This requires that all the free chemical bonds of Lanthanum are filled with Nitrogen so that the chances for interaction with the neighboring boron layers are decreased [10]. Admittedly, the passivation of Lanthanum via the magnetron deposition process in the $\mathrm{N}$ atmosphere can vigorously preserve the B-on-La interface. However, there is a risk of the formation of a BN compound at the La-on-B interface, and the chance of obtaining $\mathrm{LaB}_{\mathrm{x}}$ at that interface cannot be eliminated. As demonstrated by Kuznetsov and co-workers in Figure 9(a) [10], at the early stage of the La layer deposition in a nitrogen environment, there is a high possibility that both La and $\mathrm{N}$ atoms first contact with the boron atoms of the substrate layer rather than the formation of LaN. From Table 1, it is shown in the enthalpies of formation values that the formation of $\mathrm{LaB}_{6}$ and $\mathrm{BN}$ are thermodynamically favorable.

From the above observations, Kuznetsov designed a structure that eliminates the direct contact of $\mathrm{N}$ species with the underlying B layer at the LaN-on-B interface. It was achieved by simply introducing an initial delay in Lanthanum nitridation. This resulted in a Lanthanum interlayer at the LaN-on-B interface. Herein, the chemical interaction of La with the underlying $B$ layer will form a $\mathrm{LaB}_{\mathrm{x}}$ interlayer. To confirm the response, they modeled the reflectivity of multilayers structures with varying thicknesses of $\mathrm{LaB}_{6}$ interlayers compared to the influence of $\mathrm{BN}$ interlayers at LaN-on-B interface considering effective roughness/diffusion zones of $0.5 \mathrm{~nm}$. The results proved that $\mathrm{BN}$ interlayers resulted in a very high reflectivity decrease compared to $\mathrm{LaB}_{6}$ (Figure 9(b)). Furthermore, the synthesized $\mathrm{B} \backslash \mathrm{La} \backslash \mathrm{LaN}$ (the materials are written in the deposition array) PMMs gave 
a reflectivity of $64.1 \%$ at $\lambda=6.65 \mathrm{~nm}$ taken at $1.5^{\circ}$ off-normal AOI as seen in Figure 9(c). The increase in reflectance can be ascribed to forming a more optically favorable $\mathrm{LaB}_{6}$ instead of BN at the LaN-on-B interface.

(a)

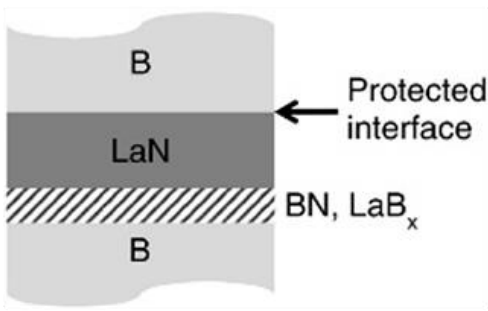

(b) 69

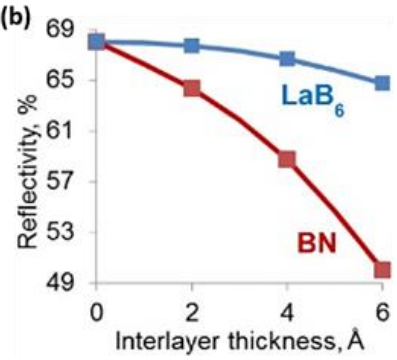

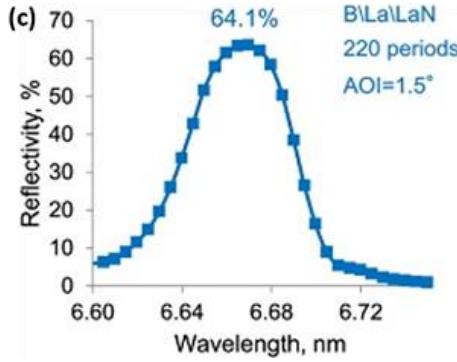

Figure. 9 (a) Simplified drawing of La/B multilayer with nitridated Lanthanum. The B-on-LaN interface is secured from chemical interaction, whereas $\mathrm{BN}$ and $\mathrm{LaB} \times \mathrm{x}$ can develop at the LaN-on-B interface. (b) Modeled peak reflectivity of the LaN/B multilayers with $\mathrm{BN}$ and $\mathrm{LaB}_{6}$ as interlayers on the LaN-on-B interface. $\lambda=6.65 \mathrm{~nm}$, AOI at $1.5^{\circ}$ off-normal incidence. (c) Measured optical reflectivity of a 220-periods B \La \LaN PMMs with La interlayers of $0.3 \mathrm{~nm}$ thickness introduced at the LaN-on-B interface. The measurement was done $1.5^{\circ}$ off-normal AOI. Reprinted with permission from [10] () The Optical Society.

\section{Thermal stability of the BEUV PMMs}

Thermal stability of lithographic multilayer optics for $\sim 7 \mathrm{~nm}$ wavelength is an essential prerequisite for performance because the optics are normally exposed to greater thermal loads (or higher power densities) than the optics used in EUV lithography sources $(\lambda$ $=13.5-\mathrm{nm}$ ) [60]. Exposure to high flux or protracted photons contributes to thermal loading, which might lead to atomic interdiffusion, and successive formation of compounds at the interfaces of multilayers $[32,61]$. This can cause the deterioration of the optical contrast of the multilayer, resulting in decreases in the reflectance [60]. Furthermore, the period-thickness of the multilayer might change due to the formation of compounds, thereby causing an imbalance between the target wavelength and the multilayer period [29]. Nanoscale multilayers are mainly susceptible to slight structural changes at the interfaces. Khorsand et al. [62] exposed Mo/Si multilayers to excessive femtosecond pulse EUV sources. They observed an ultrafast formation of molybdenum silicide because of the intensified atomic diffusion in melted Si leading to irreversible structural adjustment. The damage mechanism is akin to what is seen during thermal treatment as demonstrated by Nedelcu and co-workers [63]. Their study showed growth of silicide interfaces as Mo/Si multilayers are annealed up to $300{ }^{\circ} \mathrm{C}$.

To better understand the effect of thermal stability on PMMs, Naujok and co-workers [64] investigated the change in the microstructure and reflective properties of $\mathrm{La} / \mathrm{B} 4 \mathrm{C}$ and $\mathrm{LaN} / \mathrm{B}{ }_{4} \mathrm{C}$ PMMs prepared for high reflectivity at $\lambda=6.7 \mathrm{~nm}$ and annealed at elevated temperatures $\leq 800^{\circ} \mathrm{C}$. They analyzed the thermally induced changes in the internal structure of the PMMs such as the elemental distribution, period thickness, crystallinity, and optical reflectivity. At temperature $\leq 300^{\circ} \mathrm{C}$, there is no noticeable change in the period thickness of La/B4C PMMs. But, at temperatures $>300^{\circ} \mathrm{C}$, there is a significant decrease in the period thickness. This decrease in period thickness was ascribed to the $\mathrm{LaB}_{6}$ crystallites formation and growth. Further investigation proved that the $\mathrm{La} / \mathrm{B}_{4} \mathrm{C}$ multilayer changes to a $\mathrm{LaB}_{6} / \mathrm{C}$ multilayer after annealing at $800{ }^{\circ} \mathrm{C}$ for 10 hours. This resulted in a shift in wavelength and substantial deterioration of EUV peak reflectance. From Figure 10, it is shown that the initial reflectivity of $49.8 \%$ at $\lambda=6.7 \mathrm{~nm}$, and $8^{\circ}$ AOI after deposition decreased to $37.2 \%$ at $\lambda=6.68 \mathrm{~nm}$ after annealing at $400{ }^{\circ} \mathrm{C}$ temperature, and further decreased to $2.3 \%$ after $800{ }^{\circ} \mathrm{C}$ thermal treatment. The decreased in the optical performance was ascribed to the presence of rougher interfaces as a result of the formation of $\mathrm{LaB}_{6}$ crystallites. In confirmation, they simulated a $\mathrm{LaB}_{6} / \mathrm{C}$ multilayer considering an average interface width of 0.6 $\mathrm{nm}$, and the reflectivity was shown to be $\sim 3 \%$. For the $\mathrm{LaN} / \mathrm{B}_{4} \mathrm{C}$ PMMs, they reported a linear increase in the period thickness at up to $600{ }^{\circ} \mathrm{C}$ temperature. The period thickness 
further expanded as the temperature increases. They concluded that the increase in the period thickness results from the formation of amorphous $\mathrm{BN}$ at the interfaces of the multilayer. Additional studies confirmed no sign of crystallinity throughout the thermal treatment temperature range, and large amorphous $\mathrm{LaB}_{x} \mathrm{C}_{y}$ layers are divided by thin amorphous BN layers. Moreover, their observation on $\mathrm{LaN} / \mathrm{B} 4 \mathrm{C}$ PMMs showed a reduction in reflectivity and significant spectral shift in the peak wavelength as shown in Figure 10(d). The EUV reflectance decreased from the initial value of $57 \%(\lambda=6.7 \mathrm{~nm})$ to $50.2 \%$ after $400^{\circ} \mathrm{C}$ annealing temperature. This signifies a $12 \%$ reflection loss compared to the $25 \%$ loss seen in $\mathrm{La} / \mathrm{B}_{4} \mathrm{C}$ PMMs. Also, when the annealing temperature is $800{ }^{\circ} \mathrm{C}$ for 10 hours, the EUV reflectance is shown to be $12.6 \%(\lambda=6.96)$, corresponding to a $20 \%$ loss in reflectance. Interestingly, the researchers have previously demonstrated that LaN/B PMMs revealed a $20 \%$ reflection loss at $400{ }^{\circ} \mathrm{C}$ annealing temperature. Therefore, $\mathrm{LaN} / \mathrm{B}_{4} \mathrm{C}$ experienced minimal thermally induced reflection loss compared to the $\mathrm{La} / \mathrm{B}_{4} \mathrm{C}$ and $\mathrm{LaN} / \mathrm{B}$ PMMs.

(a)

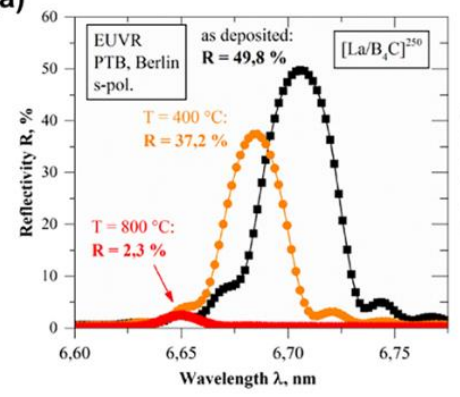

(b)

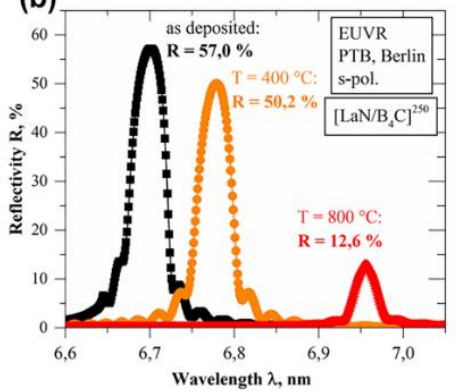

(c)

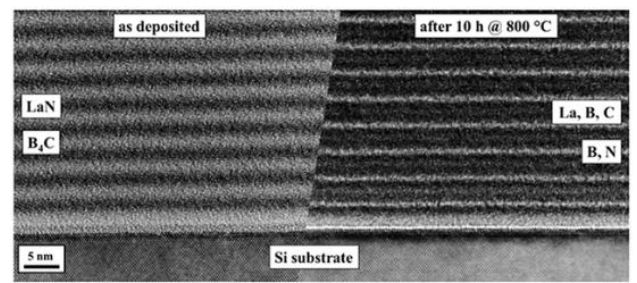

Figure 10. (a) EUV spectral of the $\mathrm{La} / \mathrm{B}_{4} \mathrm{C}$ PMMs after deposition and after annealing to $400{ }^{\circ} \mathrm{C}$ and $800{ }^{\circ} \mathrm{C}$. (b) EUV spectral of the LaN/B $\mathrm{B}_{4} \mathrm{C}$ PMMs after deposition and after annealing to $400{ }^{\circ} \mathrm{C}$ and $800{ }^{\circ} \mathrm{C}$ for 10 hours. (c) High-resolution TEM cross-sectional images of the LaN/B4 $\mathrm{C}$ PMMs after deposition (left) and after annealing at $800^{\circ} \mathrm{C}$ (right). Reprinted from [64] with permission from Elsevier.

Nyabero et al. [29] used pulsed DC magnetron sputtering to deposit 50-period $\mathrm{Mo} / \mathrm{B}_{4} \mathrm{C}$ multilayers onto neatly polished $\mathrm{Si}$ substrates. The thickness of Mo layers is $3 \mathrm{~nm}$, while the thickness of B4C layers was varied from 1 to $4 \mathrm{~nm}$. The samples were annealed up to $300{ }^{\circ} \mathrm{C}$ for 48 hours to enable significant intermixing, and the physical causes were analyzed. Their studies showed both expansion and compaction of the period thickness of the multilayers. Figure 11(a) revealed that the PMMs with $\mathrm{B}_{4} \mathrm{C}<2 \mathrm{~nm}$ exhibited compaction, while the PMMs with $\mathrm{B}_{4} \mathrm{C}>2.5 \mathrm{~nm}$ showed expansion. Moreover, PMMs with $\mathrm{B}_{4} \mathrm{C}=2 \mathrm{~nm}$ and $2.5 \mathrm{~nm}$ expanded initially before showing compaction. These results proved that the change in period thickness of $\mathrm{Mo} / \mathrm{B}_{4} \mathrm{C}$ PMMs majorly depends on the thickness of the $\mathrm{B}_{4} \mathrm{C}$ layers as well as the annealing time. Although they observed intense stress relaxation at the thermal treatment time as seen in Figure 11(b), it was shown that the contribution of stress relaxation to the expansion of the period thickness is negligible. Moreover, on the effect of interdiffusion of atoms during annealing, in PMMs with $\mathrm{B}_{4} \mathrm{C} \leq$ $1.5 \mathrm{~nm}$, the additional supply of Mo into the earlier formed $\mathrm{MoB}_{x} \mathrm{C}_{\mathrm{y}}$ (Figure 11(c)) interlayer was prevalent, leading to densification, hence, results in period thickness compaction. However, for PMMs with $\mathrm{B}_{4} \mathrm{C} \geq 2 \mathrm{~nm}$, it was reported that the higher diffusion of $\mathrm{B}$ and $C$ (the mobilities of $B$ and $C$ atoms are higher than Mo atoms) into the interlayers led to the formation of low-density compounds resulting in a thickness period expansion. 


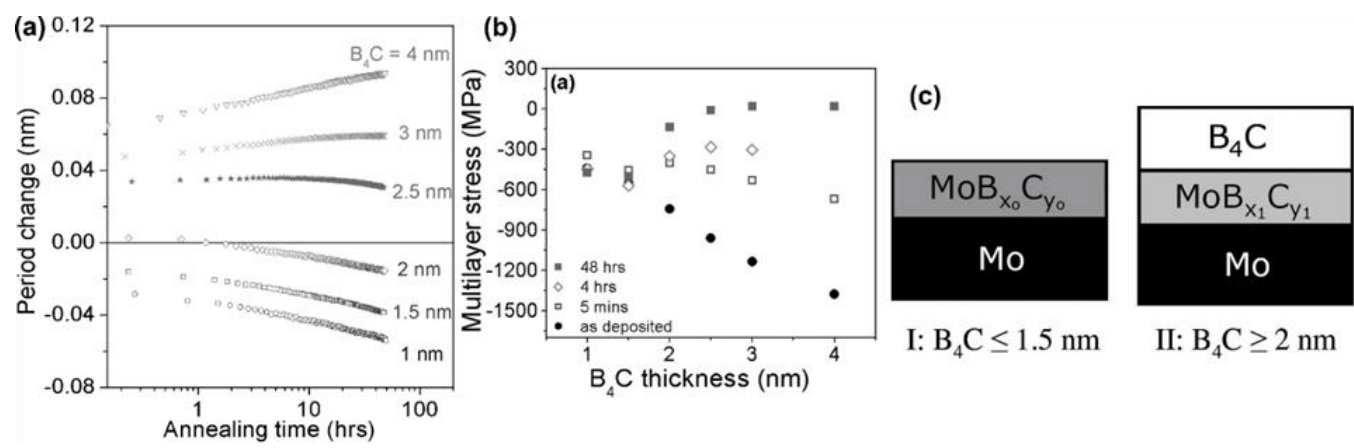

Figure 11. (a) Change in the thickness period to the annealing time at $300{ }^{\circ} \mathrm{C}$ in the $\mathrm{Mo} / \mathrm{B}_{4} \mathrm{C} \mathrm{PMMs}$. (b) The stress in the $\mathrm{Mo} / \mathrm{B}_{4} \mathrm{C}$ PMMs to the $\mathrm{B}_{4} \mathrm{C}$ thickness at the as-deposited state and different annealing times. (c) Schematic depiction of the structural differences in as-deposited $\mathrm{Mo} / \mathrm{B}_{4} \mathrm{C}$ PMMs with thicknesses. It is shown that before thermal treatment, the PMMs with $\mathrm{B}_{4} \mathrm{C} \leq 1.5 \mathrm{~nm}$ would possess no or very little pure $\mathrm{B}_{4} \mathrm{C}$, while the PMMs with $\mathrm{B}_{4} \mathrm{C} \geq 2 \mathrm{~nm}$ would still possess pure $\mathrm{B}_{4} \mathrm{C}$. Reprinted from [29] with the permission of AIP Publishing.

In place of Mo, Zhu et al. [34] use Mox $\mathrm{C}_{1-x}$ to grow 100 bilayers Mox $\mathrm{C}_{1-x} / \mathrm{B}_{4} \mathrm{C}$ PMMs on $\mathrm{Si}$ substrate to compare the effect of stress and thermal treatment. After repeated thermal treatment from $100{ }^{\circ} \mathrm{C}$ to $600{ }^{\circ} \mathrm{C}$, the $\mathrm{Mo} / \mathrm{B}_{4} \mathrm{C}$ multilayers showed a $\sim 2 \%$ decrease in reflectivity near-normal incident, whereas $\mathrm{Mox}_{1-\mathrm{x}} / \mathrm{B} \mathrm{B}_{4} \mathrm{C}$ multilayers proved to be more stable with a $1.4 \%$ decrease in reflectivity. However, the $\sim 11 \%$ reflectivity value of the as-prepared $\mathrm{Mox}_{1-\mathrm{x}} / \mathrm{B} \mathrm{B}_{4} \mathrm{C}$ multilayers made it less competitive in the choice of optical performance. Also, Rao et al. [65] demonstrated a high thermal stable W/B $\mathrm{B}_{4} \mathrm{C}$ PMMs after $800{ }^{\circ} \mathrm{C}$ annealing temperatures. They observed that there is no formation of tungsten carbide nor tungsten boride during the thermal treatments. Besides, they obtained a near-normal incidence soft x-ray reflectivity of $\sim 8.3 \%$ at $\lambda=6.8 \mathrm{~nm}$, which decreased to $\sim 7 \%$ after annealing at $800{ }^{\circ} \mathrm{C}$ indicating no architectural changes within the layers throughout the thermal treatments. Although the $\mathrm{W} / \mathrm{B}_{4} \mathrm{C}$ multilayer offered a thermal stability advantage, its theoretical and experimental reflectivity is very low compared to other BEUV PMMs which we have reviewed so far.

\section{Summary}

EUV lithography has been the dominant candidate for the manufacturing of the nextgeneration integrated circuits. However, the challenging demands of the semiconductor industry have made the BEUV lithography at $\sim 7 \mathrm{~nm}$ wavelength the outstanding candidate for patterning smaller complex features with photons [66, 67]. The choice of $\sim 7 \mathrm{~nm}$ wavelength was based on the following factors: $\sim 7 \mathrm{~nm}$ is in the range of anomalous dispersion of the optical constants of Boron (K-absorption edge at $6.63 \mathrm{~nm}$ wavelength). Expectedly, Boron-containing mirrors should give high reflection coefficients. Theoretically, $\mathrm{La} / \mathrm{B}$ PMMs give a reflectivity of $>80 \%$ at normal incidence. Also, $\mathrm{La} / \mathrm{B} 4 \mathrm{C}$ was first found to possess a theoretical reflectivity of $70 \%$ and experimental reflectivity of $>30 \%$ at normal incidences.

In this review, different factors were considered as major contributors to the variations between the theoretical and experimental reflectivities of the different PMMs models. Among them is the enlargement of the interface boundaries of the multilayer coatings due to the intermixing between layers resulting in a lower reflection peak of the PMMs. One of the remedies is the use of anti-diffusion barriers to suppress the expansion of the interface, and Carbon has been identified as the leading material for the anti-diffusion barriers. Besides, nitridation of Lanthanum can produce chemically inactive, and high contrast interfaces which will significantly reduce the intermixing between $\mathrm{La}$ and B layers in $\mathrm{La} / \mathrm{B}$ and $\mathrm{La} / \mathrm{B} 4 \mathrm{C}$ PMMs. Furthermore, high interface roughness can cause reduced reflectivity. The interface roughness can be decreased by controlling the deposition temperature, pressure, and thickness of the individual layers. Also, ion-polishing has been suggested to reduce the interface roughness. It involves an in-situ etching of the films amid growth using low-energy ions. Ion-etching can decrease the surface roughness and 
increase the optical contrast between interface boundaries through the removal of a top layer with a lesser density that would allow interdiffusion [55]. After identifying the structural limitations of PMMs and proffering solutions to optimize the experimental peak reflectivity of PMMs at $\sim 7 \mathrm{~nm}$ wavelength. The gap between the measured and calculated values is still wide particularly for $\mathrm{Mo} / \mathrm{B}$ and $\mathrm{La} / \mathrm{B}$ PMMs models. Therefore, more research and concerted efforts are still needed to efficiently design multilayer mirrors with very high reflection at $\sim 7 \mathrm{~nm}$ wavelength.

Author Contributions: Conceptualization, O.P; methodology, P.U., H.H., and O.P.; writing-original draft preparation, P.U., S.S., P.O, and O.P.; writing-review and editing, P.U., H.H., and O.P.; supervision, O.P.; funding acquisition, O.P. All authors have read and agreed to the published version of the manuscript.

Funding: This research and APC were funded by the Zhejiang University/University of Illinois at the Urbana-Champaign Institute.

Acknowledgments: This work was supported by the Zhejiang University/University of Illinois at the Urbana-Champaign Institute and supervised by Oleksiy V. Penkov

Conflicts of Interest: The authors declare no conflict of interest.

\section{References}

1. A. González, Trends in Processor Architecture in Harnessing Performance Variability / Embedded and High-performance Many/Multi-core Platforms, (2019) 23 - 42.

2. Y. Sun, N.B. Agostini, S. Dong, D. Kaeli, Summarizing CPU and GPU Design Trends with Product Data, arXiv preprint arXiv:1911.11313 (2019) -

3. A.D. Akhsakhalyan, E.B. Kluenkov, A.Y. Lopatin, V.I. Luchin, A.N. Nechay, A.E. Pestov, V.N. Polkovnikov, N.N. Salashchenko, M.V. Svechnikov, M.N. Toropov, N.N. Tsybin, N.I. Chkhalo, A.V. Shcherbakov, Current Status and Development Prospects for Multilayer X-Ray Optics at the Institute for Physics of Microstructures, Russian Academy of Sciences, Journal of Surface Investigation: X-ray, Synchrotron and Neutron Techniques 11(1) (2017) 1-19.

4. T. Manouras, P. Argitis, High Sensitivity Resists for EUV Lithography: A Review of Material Design Strategies and Performance Results, Nanomaterials (Basel) 10(8) (2020) 1593.

5. N. Fu, Y. Liu, X. Ma, Z. Chen, EUV lithography: state-of-the-art review, J. Microelectron. Manuf. 2(2) (2019) 1 - 6.

6. A. Wu, J. Kumar, Extreme ultraviolet lithography and three dimensional integrated circuit-A review, Appl. Phys. Rev. 1(1) (2014) 011104 -

7. A. Mallik, P. Debacker, G. McIntyre, R.-H. Kim, K. Ronse, EUVL Gen 2.0: key requirements for constraining semiconductor cost in advanced technology node manufacturing, SPIE2018.

8. V. Bakshi, H. Mizoguchi, T. Liang, A. Grenville, J. Benschop, Special Section Guest Editorial: EUV Lithography for the 3-nm Node and Beyond, J. Micro/Nanolith. MEMS MOEMS 16(4) (2017) 1 - 2.

9. T. Otsuka, B. Li, C. O'Gorman, T. Cummins, D. Kilbane, T. Higashiguchi, N. Yugami, W. Jiang, A. Endo, P. Dunne, G. O'Sullivan, A 6.7-nm beyond EUV source as a future lithography source, 8322 (2012) 832214 -

10. D.S. Kuznetsov, A.E. Yakshin, J.M. Sturm, R.W.E. van de Kruijs, E. Louis, F. Bijkerk, High-reflectance La/B-based multilayer mirror for 6.x nm wavelength, Opt. Lett. 40(16) (2015) 3778 - 3781.

11. D.S. Kuznetsov, A.E. Yakshin, J.M. Sturm, F. Bijkerk, Thermal stability of high-reflectance La/B-based multilayers for $6 . x \mathrm{~nm}$ wavelength, J. Appl. Phys. 122(12) (2017) 125302 -

12. D.S. Kuznetsov, A.E. Yakshin, J.M. Sturm, R.W.E. van de Kruijs, F. Bijkerk, Structure of high-reflectance La/B-based multilayer mirrors with partial La nitridation, AIP Advances 6(11) (2016) 115117 - 10.

13. B. Krause, D.S. Kuznetsov, A.E. Yakshin, S. Ibrahimkutty, T. Baumbach, F. Bijkerk, In situ and real-time monitoring of structure formation during non-reactive sputter deposition of Lanthanum and reactive sputter deposition of Lanthanum nitride, J. Appl. Crystallogr. 51(4) (2018) 1013 - 1020.

14. D. Kuznetsov, A. Yakshin, J. Sturm, F. Bijkerk, Grazing-incidence La/B-based multilayer mirrors for 6. $x$ nm wavelength, J. Nanosci. Nanotechno. 19(1) (2019) 585 - 592.

15. S. Wurm, K. Kemp, SEMATECH pushes extreme ultraviolet lithography forward, SPIE Newsroom (2006) 1 - 3.

16. E. Louis, A.E. Yakshin, P.C. Goerts, S. Oestreich, R. Stuik, E.L.G. Maas, M.J.H. Kessels, F. Bijkerk, M. Haidl, S. Muellender, M. Mertin, D. Schmitz, F. Scholze, G. Ulm, Progress in Mo/Si multilayer coating technology for EUVL optics, Proc.SPIE 3997 (2000) 0 -

17. E. Louis, A.E. Yakshin, T. Tsarfati, F. Bijkerk, Nanometer interface and materials control for multilayer EUV-optical applications, Prog. Surf. Sci. 86(11) (2011) 255 - 294.

18. O.V. Penkov, I.A. Kopylets, M. Khadem, T. Qin, X-Ray Calc: A software for the simulation of X-ray reflectivity, SoftwareX 12 (2020) 100528 - 5.

19. Q. Huang, V. Medvedev, R. van de Kruijs, A. Yakshin, E. Louis, F. Bijkerk, Spectral tailoring of nanoscale EUV and soft x-ray multilayer optics, Appl. Phys. Rev. 4(1) (2017) 011104 - 15. 
20. B. Yu, C. Jin, S. Yao, C. Li, Y. Liu, F. Zhou, B. Guo, H. Wang, Y. Xie, L. Wang, Low-stress and high-reflectance Mo/Si multilayers for extreme ultraviolet lithography by magnetron sputtering deposition with bias assistance, Appl. Optics 56(26) (2017) 7462 7468 .

21. S.S. Sakhonenkov, E.O. Filatova, A.U. Gaisin, S.A. Kasatikov, A.S. Konashuk, R.S. Pleshkov, N.I. Chkhalo, Angle resolved photoelectron spectroscopy as applied to X-ray mirrors: an in depth study of Mo/Si multilayer systems, Phys. Chem. Chem. Phys. 21(45) (2019) 25002 - 25010.

22. C. Montcalm, P.A. Kearney, J.M. Slaughter, B.T. Sullivan, M. Chaker, H. Pépin, C.M. Falco, Survey of Ti-, B-, and Y-based soft X-ray-extreme ultraviolet multilayer mirrors for the 2- to 12-nm wavelength region, Appl. Optics 35(25) (1996) 5134 - 5147.

23. U.-J.C. , U.-B.J. , U.-J.Z. , U.-S.Z. , U.-M.L. , U.-M.C. , U.-J.Z. , U.-J.Z. , Fabrication of a two-dimensional graded periodic Mo/Si multilayer mirror using magnetron sputtering technology, Proc.SPIE 11032 (2019) 0 -

24. I. Kopylets, O. Devizenko, E. Zubarev, V. Kondratenko, I. Artyukov, A. Vinogradov, O. Penkov, Short-Period Multilayer X-ray Mirrors for "Water" and "Carbon Windows" Wavelengths, J. Nanosci. Nanotechnol. 19 (2019) 518 - 531.

25. J. Zhu, J. Chen, H. Li, J. Zhang, M. Cui, Cr/C Reflective Multilayer for Wavelength of $44.8 \AA$, J. Nanosci. Nanotechno. 19(1) (2019) $609-612$.

26. M. Barthelmess, S. Bajt, Thermal and stress studies of normal incidence Mo/B4C multilayers for a $6.7 \mathrm{~nm}$ wavelength, Appl. Optics 50(11) (2011) 1610 - 1619.

27. P. Naujok, S. Yulin, A. Bianco, N. Mahne, N. Kaiser, A. Tünnermann, La/B4C multilayer mirrors with an additional wavelength suppression, Opt. Express 23(4) (2015) 4289 - 4295.

28. I.A. Makhotkin, E. Zoethout, R. van de Kruijs, S.N. Yakunin, E. Louis, A.M. Yakunin, V. Banine, S. Müllender, F. Bijkerk, Short period La/B and LaN/B multilayer mirrors for 6.8 nm wavelength, Opt. Express 21(24) (2013) 29894 - 29904.

29. L. Nyabero, W.E. van de Kruijs, E. Yakshin, Zoethout, von Blanckenhagen, Bosgra, A. Loch, Bijkerk, Interlayer growth in Mo/B4C multilayered structures upon thermal annealing, J. Appl. Phys. 113(14) (2013) 144310 -

30. C. Morawe, R. Supruangnet, J.-C. Peffen, Structural modifications in Pd/B4C multilayers for X-ray optical applications, Thin Solid Films 588 (2015) 1 - 10.

31. D. Dellasega, V. Russo, A. Pezzoli, C. Conti, N. Lecis, E. Besozzi, M. Beghi, C.E. Bottani, M. Passoni, Boron films produced by high energy Pulsed Laser Deposition, Mater. Design 134 (2017) 35 - 43.

32. I. Chkhalo, Künstner, N. Polkovnikov, N. Salashchenko, Schäfers, D. Starikov, High performance La/B4C multilayer mirrors with barrier layers for the next generation lithography, Appl. Phys. Lett. 102(1) (2013) 011602 -

33. I.A. Kopylets, V.V. Kondratenko, E.N. Zubarev, D.L. Voronov, E.M. Gullikson, E.A. Vishnyakov, E.N. Ragozin, Fabrication and characterization of Sb/B4C multilayer mirrors for soft X-rays, Appl. Surf. Sci. 307 (2014) 360 - 364.

34. J. Zhu, B. Ji, J. Zhu, H. Jiang, S. Zhu, M. Li, J. Zhang, Studies on the stress and thermal properties of Mo/B4C and MoxC1-x/B4C multilayers, Mater. Res. Express 7(3) (2020) 036403 -

35. A.V. Vinogradov, Multilayer X-ray optics, Quantum Electron. 32(12) (2002) 1113 - 1114.

36. T.W. Barbee, Multilayer X-ray optics, Opt. Eng. 25 (1986) 899 - 915.

37. J. Zhu, B. Ji, H. Jiang, J. Zhu, S. Zhu, M. Li, J. Zhang, Interface study of Sc/Si multilayers, Appl. Surf. Sci. 515 (2020) 146066 -

38. D.L. Voronov, E.N. Zubarev, V.V. Kondratenko, Y.P. Pershin, V.A. Sevryukova, Y.A. Bugayev, Study of fast diffusion species in Sc/Si multilayers by W-based marker analysis, Thin Solid Films 513(1-2) (2006) 152 - 158.

39. Y. Yuan, K. Le Guen, C. Mény, C. Bouillet, J. Zhu, Z. Wang, P. Jonnard, Evolution of interfacial structure of Co-based periodic multilayers upon annealing, Surf. Coat. Technol. 352 (2018) 508 - 512.

40. G. Sertsu, Giglia, Brose, Park, S. Wang, Mayer, Juschkin, Nicolosi, Deposition and characterization of B4C/CeO2 multilayers at 6.x nm extreme ultraviolet wavelengths, J. Appl. Phys. 119(9) (2016) 095301 -

41. J. Zhu, J. Zhang, H. Jiang, J. Zhu, S. Zhu, M. Li, B. Ji, J. Zhao, Interface Study on the Effect of Carbon and Boron Carbide Diffusion Barriers in Sc/Si Multilayer System, ACS App. Mater. Interface. 12(22) (2020) 25400 - 25408.

42. P. Pershyn Yu., Y. Devizenko A., N. Zubarev E., V. Kondratenko V., L. Voronov D., M. Gullikson E., Scandium-silicon Multilayer X-ray Mirrors with CrB2 Barrier LayersScSiCrB, J. Nano Elec. Phys. 10(5) (2018) 05025 - 1-05025-6.

43. J. Zhu, J. Zhang, H. Li, Y. Tu, J. Chen, H. Wang, S.S. Dhesi, M. Cui, J. Zhu, P. Jonnard, Improving the soft X-ray reflectivity of Cr/Ti multilayers by co-deposition of B4C, J. Synchrotron Radiat. 27(6) (2020) 1614 - 1617.

44. O.V. Penkov, I.A. Kopylets, V.V. Kondratenko, M. Khadem, Synthesis and structural analysis of Mo/B periodical multilayer Xray mirrors for beyond extreme ultraviolet optics, Mater. Design 198 (2021) 109318 - 8.

45. Y.P. Pershyn, E.M. Gullikson, V.V. Kondratenko, V.V. Mamon, S.A. Reutskaya, D.L. Voronov, E.N. Zubarev, I.A. Artyukov, A.V. Vinogradov, Effect of working gas pressure on interlayer mixing in magnetron-deposited Mo/Si multilayers, Opt. Eng. 52(9) (2013) $095104-$

46. H. Jiang, H. Wang, J. Zhu, C. Xue, J. Zhang, N. Tian, A. Li, Thickness-dependent structural characteristics for a sputteringdeposited chromium monolayer and $\mathrm{Cr} / \mathrm{C}$ and $\mathrm{Cr} / \mathrm{Sc}$ multilayers, J. Synchrotron Radiat. 25(3) (2018) 785 - 792.

47. U. Kleineberg, T. Westerwalbesloh, W. Hachmann, U. Heinzmann, J. Tümmler, F. Scholze, G. Ulm, S. Müllender, Effect of substrate roughness on Mo/Si multilayer optics for EUVL produced by UHV-e-beam evaporation and ion polishing, Thin Solid Films 433(1) (2003) 230 - 236.

48. A. Guggenmos, S. Radünz, R. Rauhut, M. Hofstetter, S. Venkatesan, A. Wochnik, E.M. Gullikson, S. Fischer, B. Nickel, C. Scheu, U. Kleineberg, Ion polished $\mathrm{Cr} / \mathrm{Sc}$ attosecond multilayer mirrors for high water window reflectivity, Opt. Express 22(22) (2014) 26526 - 26536.

49. V. Medvedev, V. Nikolaev, A. Zameshin, IJpes, A. Makhotkin, N. Yakunin, E. Yakshin, Bijkerk, Low-energy ion polishing of Si in W/Si soft X-ray multilayer structures, J. Appl. Phys. 126(4) (2019) 045302 - 
50. D. Xu, Q. Huang, Y. Wang, P. Li, M. Wen, P. Jonnard, A. Giglia, I.V. Kozhevnikov, K. Wang, Z. Zhang, Z. Wang, Enhancement of soft X-ray reflectivity and interface stability in nitridated Pd/Y multilayer mirrors, Opt. Express 23(26) (2015) 33018 - 33026.

51. Q. Huang, Y. Liu, Y. Yang, R. Qi, Y. Feng, I.V. Kozhevnikov, W. Li, Z. Zhang, H. Jiang, L. Zhang, A. Li, J. Wang, Z. Wang, Nitridated Ru/B4C multilayer mirrors with improved interface structure, zero stress, and enhanced hard X-ray reflectance, Opt. Express 26(17) (2018) 21803 - 21812.

52. Y. Platonov, J. Rodriguez, M. Kriese, E. Gullikson, T. Harada, T. Watanabe, H. Kinoshita, Multilayers for next generation EUVL at 6.X nm, SPIE2011.

53. S.S. Andreev, M.M. Barysheva, N.I. Chkhalo, S.A. Gusev, A.E. Pestov, V.N. Polkovnikov, N.N. Salashchenko, L.A. Shmaenok, Y.A. Vainer, S.Y. Zuev, Multilayered mirrors based on La/B4C(B9C) for X-ray range near anomalous dispersion of boron $(\lambda \approx 6.7 \mathrm{~nm})$, Nuclear Instruments and Methods in Physics Research Section A: Accelerators, Spectrometers, Detectors and Associated Equipment 603(1) (2009) 80-82.

54. T. Tsarfati, R.W.E. van de Kruijs, E. Zoethout, E. Louis, F.J.T.S.F. Bijkerk, Reflective multilayer optics for $6.7 \mathrm{~nm}$ wavelength radiation sources and next generation lithography, 518 (2009) 1365.

55. N.I. Chkhalo, S. Kunstner, V.N. Polkovnikov, N.N. Salashchenko, F. Schafers, S.D. Starikov, High performance La/B4C multilayer mirrors with barrier layers for the next generation lithography, Appl Phys Lett 102(1) (2013) 011602.

56. I. Nedelcu, R.W.E. van de Kruijs, A.E. Yakshin, F. Bijkerk, Microstructure of Mo/Si multilayers with B4C diffusion barrier layers, Appl. Opt. 48(2) (2009) 155-160.

57. T. Tsarfati, R.W.E. van de Kruijs, E. Zoethout, E. Louis, F. Bijkerk, Nitridation and contrast of B4C/La interfaces and X-ray multilayer optics, Thin Solid Films 518(24) (2010) 7249-7252.

58. H.L. Bai, E.Y. Jiang, Raman scattering investigation of CN in annealed CoN/CN soft-x-ray multilayers, Journal of Physics: Condensed Matter 10(15) (1998) 3433-3448.

59. D.L. Windt, IMD-Software for modeling the optical properties of multilayer films, Computers in Physics 12(4) (1998).

60. S. Nyabero, R. van de Kruijs, A. Yakshin, I. Makhotkin, J. Bosgra, F. Bijkerk, Diffusion-induced structural changes in La/B-based multilayers for 6.7-nm radiation, 13 \%J Journal of Micro/Nanolithography, MEMS, and MOEMS(1) (2014) 013014.

61. E. Louis, A.E. Yakshin, T. Tsarfati, F. Bijkerk, Nanometer interface and materials control for multilayer EUV-optical applications, Progress in Surface Science 86(11) (2011) 255-294.

62. A.R. Khorsand, R. Sobierajski, E. Louis, S. Bruijn, E.D. van Hattum, R.W.E. van de Kruijs, M. Jurek, D. Klinger, J.B. Pelka, L. Juha, T. Burian, J. Chalupsky, J. Cihelka, V. Hajkova, L. Vysin, U. Jastrow, N. Stojanovic, S. Toleikis, H. Wabnitz, K. Tiedtke, K. Sokolowski-Tinten, U. Shymanovich, J. Krzywinski, S. Hau-Riege, R. London, A. Gleeson, E.M. Gullikson, F. Bijkerk, Single shot damage mechanism of Mo/Si multilayer optics under intense pulsed XUV-exposure, Optics Express 18(2) (2010) 700-712.

63. I. Nedelcu, R.W.E. van de Kruijs, A.E. Yakshin, F. Bijkerk, Temperature-dependent nanocrystal formation in $\$ \backslash$ mathrm $\{$ Mo $\backslash$ mathrm $\{$ Si $\} \$$ multilayers, Physical Review B 76(24) (2007) 245404.

64. P. Naujok, K. Murray, S. Yulin, C. Patzig, N. Kaiser, A. Tünnermann, Thermal stability of B-based multilayer mirrors for next generation lithography, Thin Solid Films 642 (2017) 252-257.

65. P.N. Rao, S.K. Rai, M. Nayak, G.S. Lodha, Stability and normal incidence reflectivity of W/B4C multilayer mirror near the boron K absorption edge, Appl. Opt. 52(25) (2013) 6126-6130.

66. G. Tallents, E. Wagenaars, G. Pert, Lithography at EUV wavelengths, Nature Photonics 4(12) (2010) 809-811.

67. N. Mojarad, J. Gobrecht, Y. Ekinci, Beyond EUV lithography: a comparative study of efficient photoresists' performance, Scientific Reports 5(1) (2015) 9235. 